\title{
Attribution of observed surface humidity changes to human influence
}

\author{
Katharine M. Willett ${ }^{1,2}$, Nathan P. Gillett ${ }^{1}$, Philip D. Jones ${ }^{1} \&$ Peter W. Thorne $^{2}$
}

Water vapour is the most important contributor to the natural greenhouse effect, and the amount of water vapour in the atmosphere is expected to increase under conditions of greenhouse-gasinduced warming, leading to a significant feedback on anthropogenic climate change $\mathrm{e}^{1-3}$. Theoretical and modelling studies predict that relative humidity will remain approximately constant at the global scale as the climate warms, leading to an increase in specific humidity ${ }^{1,4,5}$. Although significant increases in surface specific humidity have been identified in several regions ${ }^{6-9}$, and on the global scale in non-homogenized data ${ }^{10}$, it has not been shown whether these changes are due to natural or human influences on climate. Here we use a new quality-controlled and homogenized gridded observational data set of surface humidity, with output from a coupled climate model, to identify and explore the causes of changes in surface specific humidity over the late twentieth century. We identify a significant global-scale increase in surface specific humidity that is attributable mainly to human influence. Specific humidity is found to have increased in response to rising temperatures, with relative humidity remaining approximately constant. These changes may have important implications, because atmospheric humidity is a key variable in determining the geographical distribution ${ }^{11-13}$ and maximum intensity ${ }^{14}$ of precipitation, the potential maximum intensity of tropical cyclones ${ }^{15}$, and human heat stress ${ }^{16}$, and has important effects on the biosphere ${ }^{17}$ and surface hydrology ${ }^{17,18}$.

We use a new gridded observational data set of surface specific humidity, HadCRUH ${ }^{19}$, described in more detail in the Methods section. Global mean specific humidity, calculated from monthly anomalies over grid points with at least $75 \%$ of monthly means present, is shown by a continuous black line in Fig. 1 for the period 1973-2002. Over this period the observed global mean specific humidity in this data set increased by $0.07 \mathrm{~g} \mathrm{~kg}^{-1}$ per decade. This is similar to the 1976-2004 trend in global mean surface specific humidity of $0.06 \mathrm{~g} \mathrm{~kg}^{-1}$ per decade previously calculated from non-homogenized data ${ }^{10}$. The 1997-1999 mean is slightly higher than the 2000-2002 mean probably because of the large El Niño in 1997-1998, which strongly warmed the tropics and thereby substantially increased global mean specific humidity ${ }^{19}$.

We compare observed variations in surface specific humidity with simulated variations from two four-member ensembles of the third Hadley Centre Coupled Model $(\operatorname{HadCM} 3)^{20}$ with anthropogenic forcings only (ANT) and natural forcings only (NAT) $)^{21}$ over the period 1973-1999. This model exhibits realistic variability in global mean surface specific humidity (Supplementary Fig. 2). In the absence of archived surface specific humidity from the model's simulations with combined anthropogenic and natural forcing, we compare observed changes with the sum of the anthropogenic and natural responses. The summed anthropogenic and natural response shows an upward trend similar to that observed, and reproduces some of the interannual variability seen in the observations (Fig. 1, solid red line). We expect that such a linear sum represents a good approximation of the simulated response to combined anthropogenic and natural forcing, because the simulated temperature response to individual forcings is generally found to add linearly ${ }^{22}$, and although the specific humidity $q$ has an exponential dependence on temperature, a linear approximation is probably valid for the relatively small temperature anomalies considered here. Comparison with the separate ANT and NAT responses suggests that the observed upward trend is due mainly to anthropogenic forcing.

An increase in global mean specific humidity may reflect one of the following: a warming under conditions of constant relative humidity, an increase in relative humidity under conditions of constant temperature, a change in the geographical distribution of relative humidity under conditions of constant temperature, or some combination of these. To identify the changes in specific humidity directly associated with temperature changes, we use the gridded observational temperature data set HadCRUT3 (refs 23, 24) and an integrated form of the Clausius-Clapeyron equation (Methods) to calculate the specific humidity for each month and grid point, assuming constant climatological relative humidity and dry-air surface pressure. Temperature changes are found to explain the trend and variability well in both the observations (Fig. 1, dotted black line),

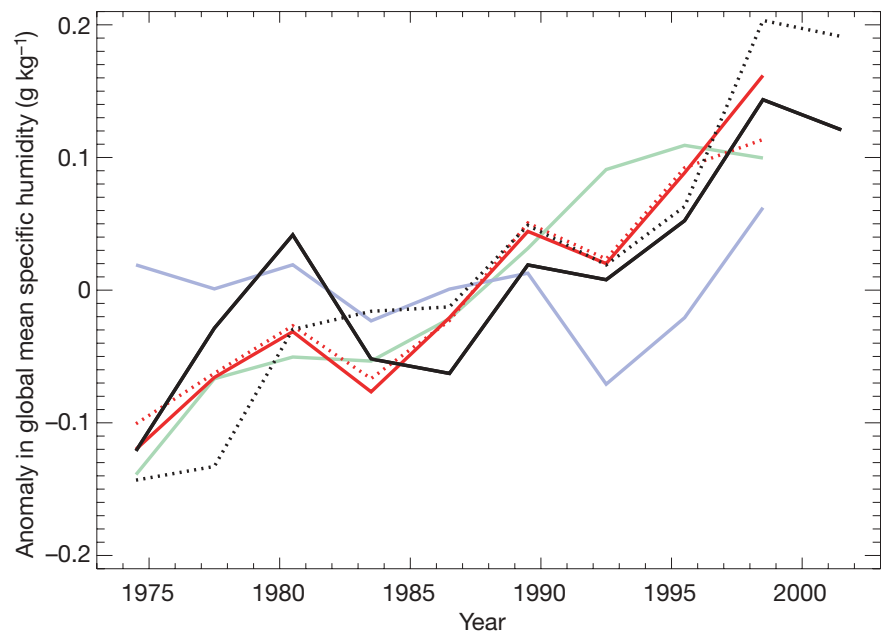

Figure 1 | Simulated and observed anomalies of global mean surface specific humidity. Non-overlapping three-year mean anomalies in global mean specific humidity in HadCRUH (solid black), and ensemble means of HadCM3 simulations of the response to natural forcing (blue),

anthropogenic forcing (green), and the sum of the two (solid red). Dotted lines show changes in specific humidity due to temperature changes under conditions of constant relative humidity from observations (dotted black), and HadCM3 (dotted red). 

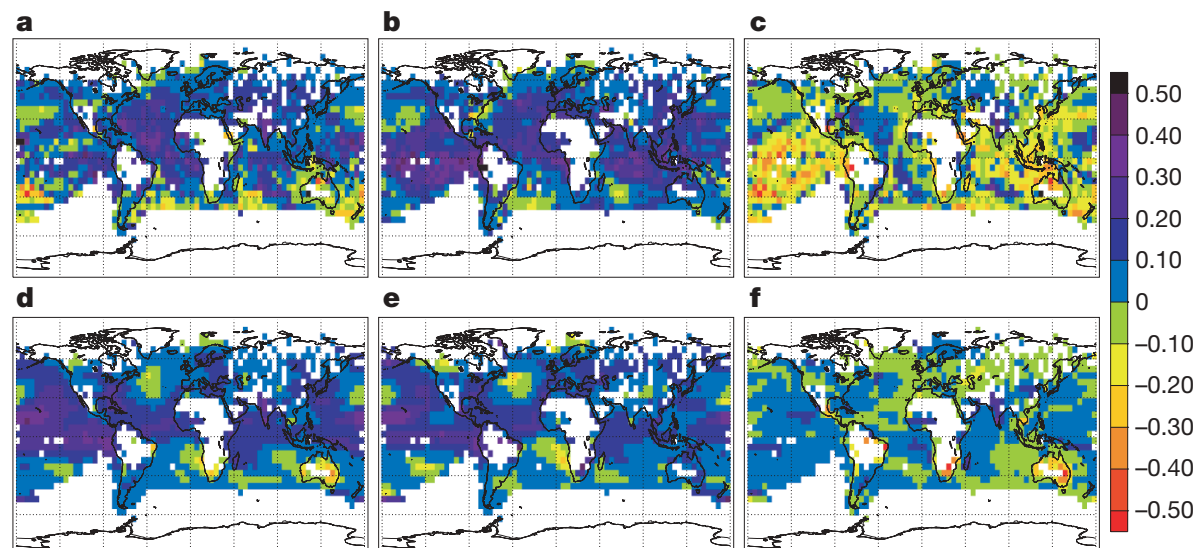

Figure 2 | Observed (top row) and simulated (bottom row) trends in specific humidity over the period 1973-1999, in $\mathrm{g} \mathrm{kg}^{-1}$ per decade. Observed trends in $q$ (a), and the sum of trends simulated in response to anthropogenic and natural forcing (d), are compared with trends calculated

and the simulated ANT+NAT response (Fig. 1, dotted red line). Agreement is particularly close in the model, which may be explained partly by the fact that the simulated response is an ensemble mean. If we assume that specific humidity anomalies contain a temperatureforced component and an independent random component, we would expect the variance of the random residual to be one-quarter the size for a four-member ensemble mean, and half the size for the sum of two four-member ensemble means as we have here. On this basis, we would expect the average distance between solid and dotted black lines to be a factor $\sqrt{2}$ larger than the average distance between the solid and dotted red lines. The fact that this difference for the observations is more than a factor $\sqrt{2}$ larger than this difference for the model may be due in part to an apparent positive bias in marine humidity data before 1982 (Methods). Alternatively, temperature and specific humidity may be too closely correlated in the model ${ }^{10}$. Nonetheless the upward trend in $q$ and the close correlation between $q$ and temperature provide an additional piece of independent evidence corroborating the recent rapid warming seen in surface temperature.

The spatial pattern of specific humidity trends is also broadly consistent between the model and observations (Fig. 2a, d), and the largest increases in specific humidity are over the tropics. As a result of the approximately exponential dependence of saturation vapour pressure on temperature, a larger response of specific humidity is expected for a given change in temperature in warmer regions, under conditions of constant relative humidity. Consistent with this expectation is the observation that increases in $q$ in the Northern Hemisphere are largest in the summer ${ }^{19}$. Increasing trends in specific humidity have been observed over most of the globe, with the main exceptions being Australia and parts of the Southern Ocean. The broad pattern of trends in specific humidity is found to be well explained by temperature trends (Fig. 2b, e). Residual changes in $q$ are generally small in the model (Fig. 2f) but are predominantly negative in the observations (Fig. 2c). Decreases over much of the tropical oceans indicate a decrease in relative humidity in these regions: a consistent picture is obtained by examining relative humidity directly, and may relate in part to an apparent positive bias in marine humidity measurements before 1982 (Methods). Although simulated and observed residual trends seem consistent in some regions (for example, drying over Australia, moistening over India), the regression coefficient of the observed residual trends against the simulated residual trends is close to zero, indicating no detectable change in relative humidity ${ }^{25}$.

To test objectively for the presence of an anthropogenic or natural response in observations of $q$, we used a detection and attribution analysis to compare simulated and observed changes ${ }^{26,27}$. After sampling the model in grid boxes in which monthly observed specific from observed (b) and simulated (e) temperature changes under the assumption of constant relative humidity; the residual (actual trend minus temperature-induced trend) is shown in $\mathbf{c}$ and $\mathbf{f}$.

humidity anomalies were present, we took non-overlapping threeyear means of simulated and observed anomalies in specific humidity over the common period of simulations and observations of 19731999 and projected onto the 25 lowest-order (T4) spherical harmonics to retain only the largest spatial scales in our analysis ${ }^{26}$. We regressed the observed spatio-temporal pattern of specific humidity anomalies against the simulated response to anthropogenic and natural forcings using a total least-squares optimal regression ${ }^{27}$ and a projection of the simulated and observed spatio-temporal patterns onto the first 30 empirical orthogonal functions (EOFs) of the control simulation, although results were robust to variations in this EOF truncation (Supplementary Fig. 3). Internal variability was estimated from 1,200 years of HadCM3 control simulation: half was used to estimate EOFs, and half to assess uncertainties in the regression coefficients. Both ANT and NAT regression coefficients were found to be inconsistent with zero (Fig. 3), indicating a detectable response to both anthropogenic and natural forcing. The ANT regression coefficient was found to be consistent with one, and residual variability was found to be consistent with control variability, indicating

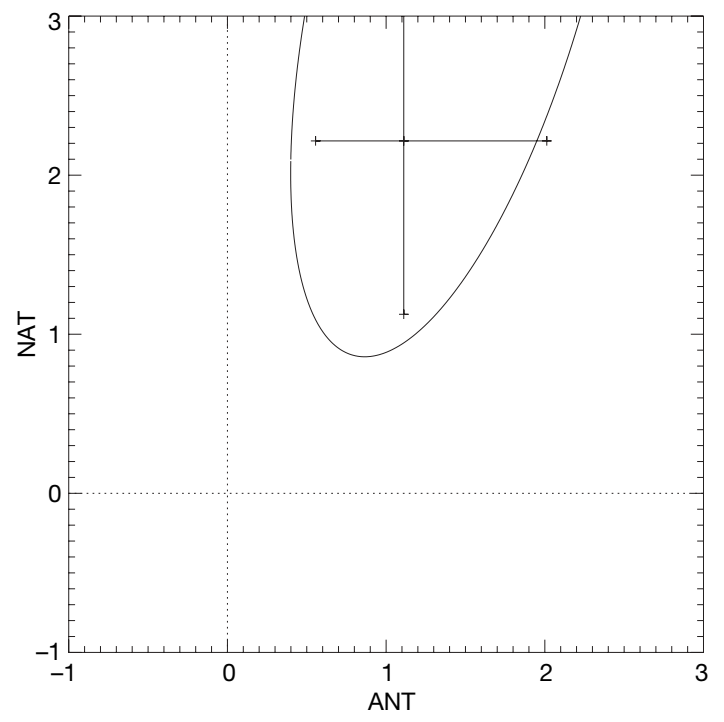

Figure 3 | Regression coefficients of observed specific humidity anomalies against the simulated response to anthropogenic ( $x$ axis) and natural ( $y$ axis) forcing. Results are based on nine three-year mean anomalies over the period 1973-1999 projected onto T4 spherical harmonics. One-dimensional $5-95 \%$ uncertainty ranges and a curve enclosing $90 \%$ of the estimated joint distribution are shown. 
consistency between simulations and observations ${ }^{28}$, although the NAT regression coefficient was found to be larger than one, suggesting that the natural response may be underestimated in the model. The natural response is probably dominated by volcanoes, which induce a global cooling for two to three years after major eruptions, which in turn decreases $q$ (ref. 29). The response to both anthropogenic and natural forcing was detected in zonal means and T4 spherical harmonics over a large range of EOF truncations (Supplementary Fig. 3), and an anthropogenic response was also detectable in the global mean alone.

The results presented here add to an increasing body of evidence that atmospheric water vapour has exhibited a significant upward trend over recent decades ${ }^{10,12,29,30}$. Although such a moistening has long been predicted as a response to warming induced by greenhouse gases $^{1,4}$, this study demonstrates that the observed increase in surface specific humidity is directly attributable to anthropogenic influence and is distinct from the predicted response to natural forcing. The pattern of observed increases in specific humidity is largely consistent with the response to observed warming under conditions of constant relative humidity ${ }^{10,25}$. Recent results indicate that the precipitation response to anthropogenic forcing may be underestimated in climate models ${ }^{12,13}$; our demonstration of consistency between the simulated and observed specific humidity response to anthropogenic influence may be useful in identifying the reasons for this discrepancy and for constraining predictions of future hydrological change. Although radiative forcing of the climate is dominated by changes in the amount of water vapour in the upper troposphere ${ }^{4}$, anthropogenic moistening of the surface and lower atmosphere is likely to have important implications for extreme precipitation, tropical cyclones and human heat stress.

\section{METHODS SUMMARY}

HadCRUH contains monthly mean $q$ and relative humidity at $5^{\circ} \times 5^{\circ}$ resolution over the period 1973-2003 and is derived principally from land and marine measurements of dewpoint temperature. Observations are quality-controlled and homogenized before being included in the data set. There is some evidence of a positive bias in the marine specific humidity data before 1982 (refs 19, 25). Analysis suggests that this bias relates to changes in recording practice. Although we suggest that this issue should be further investigated when this data set is updated, we note that this bias would tend to reduce the calculated observed trend in $q$ and would therefore lead to a conservative bias in the detection results presented here.

Full Methods and any associated references are available in the online version of the paper at www.nature.com/nature.

\section{Received 29 March; accepted 30 August 2007.}

1. Arrhenius, S. On the influence of carbonic acid in the air upon the temperature of the ground. Phil. Mag. (5) 41, 237-276 (1896).

2. Hansen, J. et al. Climate sensitivity: Analysis of feedback mechanisms. Geophys. Monogr. 29, 130-163 (1984).

3. Alley, R. et al. Climate change 2007: The Physical Science Basis, Summary for Policymakers (IPCC, Geneva, 2007).

4. Held, I. M. \& Soden, B. J. Water vapor feedback and global warming. Annu. Rev. Energy Environ. 25, 441-475 (2000).

5. Sherwood, S. C. \& Meyer, C. L. The general circulation and robust relative humidity. J. Clim. 19, 6278-6290 (2006).

6. Robinson, P. J. Temporal trends in United States dew point temperatures. Int. J. Climatol. 20, 985-1002 (2000).

7. Wang, J. X. L. \& Gaffen, D. J. Late-twentieth-century climatology and trends of surface humidity and temperature in China. J. Clim. 14, 2833-2845 (2001).

8. Philipona, R., Durr, B., Marty, C., Ohmura, A. \& Wild, M. Radiative forcingmeasured at Earth's surface-corroborate the increasing greenhouse effect. Geophys. Res. Lett. 31, 10.1029/2003GL018765 (2004).
9. Ishii, M., Shouji, A., Sugimoto, S. \& Matsumoto, T. Objective analyses of seasurface temperature and marine meteorological variables for the 20th century using ICOADS and Kobe collection. Int. J. Climatol. 25, 865-879 (2005).

10. Dai, A. Recent climatology, variability, and trends in global surface humidity. J. Clim. 19, 3589-3606 (2006).

11. Held, I. M. \& Soden, B. J. Robust responses of the hydrological cycle to global warming. J. Clim. 19, 5686-5699 (2006).

12. Wentz, F. J., Ricciardulli, L., Hilburn, K. \& Mears, C. How much more rain will global warming bring? Science 317, 233-235 (2007).

13. Zhang, X. et al. Detection of human influence on twentieth-century precipitation trends. Nature 448, 461-465 (2007).

14. Allen, M. R. \& Ingram, W. J. Constraints on future changes in climate and the hydrologic cycle. Nature 419, 224-232 (2002).

15. Holland, G. J. The maximum potential intensity of tropical cyclones. J. Atmos. Sci. 54, 2519-2541 (1997).

16. Steadman, R. G. A universal scale of apparent temperature. J. Clim. Appl. Meteorol. 23, 1674-1687 (1984).

17. Arnell, N. et al. in Climate Change 2001: Impacts, Adaptation and Vulnerability (eds McCarthy, J. J. et al.) 191-233 (Cambridge Univ. Press, Cambridge, 2001).

18. Gedney, N. et al. Detection of a direct carbon dioxide effect in continental river runoff records. Nature 439, 835-838 (2006).

19. Willett, K. M. Creation and Analysis of HadCRUH: A New Global Surface Humidity Dataset. PhD thesis, Univ. East Anglia (2007).

20. Gordon, C. et al. The simulation of SST, sea ice extents and ocean heat transports in a version of the Hadley Centre coupled model without flux adjustments. Clim. Dyn. 16, 147-168 (2000).

21. Johns, T. C. et al. Anthropogenic climate change for 1860 to 2100 simulated with the HadCM3 model under updated emissions scenarios. Clim. Dyn. 20, 583-612 (2003).

22. Gillett, N. P., Wehner, M. F., Tett, S. F. B. \& Weaver, A. J. Testing the linearity of the response to combined greenhouse gas and sulphate aerosol forcing. Geophys. Res. Lett. 31, 10.1029/2004GL020111 (2004).

23. Brohan, P., Kennedy, J. J., Harris, I., Tett, S. F. B. \& Jones, P. D. Uncertainty estimates in regional and global observed temperature changes: A new data set from 1850. J. Geophys. Res. 111, 10.1029/2005JD006548 (2006).

24. Jones, P. D., New, M., Parker, D. E., Martin, S. \& Rigor, I. G. Surface air temperature and its changes over the past 150 years. Rev. Geophys. 37, 173-199 (1999).

25. McCarthy, M. P. \& Willett, K. M. Report on Estimates of Observational Uncertainty in Surface Humidity and Free-atmosphere Temperature and Humidity Data. Technical Report No. 71 (Hadley Centre, Exeter, 2006).

26. Stott, P. A. et al. External control of 20 th century temperature by natural and anthropogenic forcings. Science 290, 2133-2137 (2000).

27. Allen, M. R. \& Stott, P. A. Estimating signal amplitudes in optimal fingerprinting. Part I: Theory. Clim. Dyn. 21, 477-491 (2003).

28. Allen, M. R. \& Tett, S. F. B. Checking for model consistency in optimal fingerprinting. Clim. Dyn. 15, 419-434 (1999).

29. Santer, B. D. et al. Identification of human-induced changes in atmospheric moisture content. Proc. Natl Acad. Sci. USA 104, 15248-15253 (2007).

30. Trenberth, K. E., Fasullo, J. \& Smith, L. Trends and variability in column-integrated atmospheric water vapor. Clim. Dyn. 24, 741-758 (2005).

Supplementary Information is linked to the online version of the paper at www.nature.com/nature.

Acknowledgements We thank P. Stott and D. Fereday for help in obtaining $\mathrm{HadCM} 3$ control data; B. Santer for advice and discussion; and M. Allen for the use of his optimal detection code. K.M.W. was supported by a CASE studentship from the UK Natural Environment Research Council and the Met Office. N.P.G. and P.D.J. acknowledge support from the Climate Change Detection and Attribution Project, jointly funded by NOAA's Office of Global Programs and the US Department of Energy. N.P.G. also acknowledges the support of the Leverhulme Trust. P.D.J. acknowledges the support of the Office of Science, US Department of Energy. P.W.T. was supported by the Department of the Environment, Food and Rural Affairs.

Author Contributions K.M.W. compiled HadCRUH during a PhD project supervised by the other three authors, and prepared the Methods section. N.P.G. performed the detection and attribution analysis and prepared the remainder of the manuscript. P.D.J. proposed the PhD project, and provided advice and guidance. P.W.T. provided advice and guidance and facilitated access to Met Office observations and model data.

Author Information Reprints and permissions information is available at www.nature.com/reprints. Correspondence and requests for materials should be addressed to N.P.G. (n.gillett@uea.ac.uk). 


\section{METHODS}

HadCRUH is a new data set of monthly mean surface humidity anomalies at $5^{\circ} \times 5^{\circ}$ resolution, covering the period $1973-2003$, with respect to the 19742003 climatology ${ }^{19}$ (available at http://www.hadobs.org). It is nearly global in coverage, combining land data from observing stations and marine data from ships, buoys and observing platforms. The land data are sourced from version 2 of the integrated surface data set, supplied by the National Climatic Data Center $^{31}$. The marine data are sourced from release 2.1 of ICOADS (International Comprehensive Ocean-Atmosphere Data Set) ${ }^{32}$ for 1973-1997 and from NCEP GTS data (Global Telecommuni-

cations System data made available through NOAA's National Centers for Environmental Prediction) for 1998-2003. Spatial coverage and observing frequencies are shown for the land and marine data in Supplementary Fig. 1.

HadCRUH is available in specific humidity $(q)$ and relative humidity (RH). All data originate from simultaneous hourly temperature $(T)$ and dewpoint temperature $\left(T_{\mathrm{dw}}\right)$ (in ${ }^{\circ} \mathrm{C}$ ). Depending on whether the temperature is above or below the freezing point, $T_{\mathrm{dw}}$ was first used to calculate vapour pressure with respect to either water $\left(e_{\mathrm{w}}\right)$ or ice $\left(e_{\mathrm{i}}\right)^{33}$ :

$$
\begin{aligned}
& e_{\mathrm{w}}=6.1121\left(1.0007+3.46 \times 10^{-6} P\right) \exp \left[\frac{\left(18.729-T_{\mathrm{dw}} / 227.3\right) T_{\mathrm{dw}}}{257.87+T_{\mathrm{dw}}}\right] \\
& e_{\mathrm{i}}=6.1115\left(1.0003+4.18 \times 10^{-6} P\right) \exp \left[\frac{\left(23.036-T_{\mathrm{dw}} / 333.7\right) T_{\mathrm{dw}}}{279.82+T_{\mathrm{dw}}}\right]
\end{aligned}
$$

The saturation vapour pressure $e_{\mathrm{s}}$, with repect to water or ice, was calculated by replacing $T_{\mathrm{dw}}$ with $T$ in the above equations. $q$ and $\mathrm{RH}$ were then found $\mathrm{d}^{34}$ :

$$
\begin{gathered}
q=1000\left[\frac{\varepsilon e}{P-(1-\varepsilon) e}\right] \\
\mathrm{RH}=100 e / e_{\mathrm{s}}
\end{gathered}
$$

where $e=e_{\mathrm{w}}$ if $T>0{ }^{\circ} \mathrm{C}$ and $e=e_{\mathrm{i}}$ if $T<0{ }^{\circ} \mathrm{C} ; \varepsilon=0.622$; and $P=1,013-Z_{\mathrm{s}} / 10$, where $Z_{\mathrm{s}}$ is the height in metres at which the observation was made.

All land data were quality controlled, taking into account issues specific to humidity such as drying and freezing of the wet-bulb thermometer, and converted into pentad mean (five-day average) $q$ and RH station time series. The quality control procedure removed about $10 \%$ of all values. The land data were subsequently homogenized by identifying and adjusting breakpoints relative to a background composite neighbour series. The process of breakpoint identification was based on a Kolomogorov-Smirnov test applied to the station minus neighbour composite series and a subjective assessment of the break's origin. Adjustments were made relative to the composite neighbour series rather than to the station series in isolation, to retain any climate change signal better. This method was shown to be effective at removing spurious jumps without introducing additional jumps for a set of case study stations. The land data were gridded by using simple (non-weighted) averaging over each grid box. The resulting gridded products were more spatially homogeneous in both $q$ and RH than those derived from the raw data.

The marine data were checked for homogeneity, and observations were removed that lay outside a plausible range compared with neighbouring observations, following the convention of the Hadley Centre Marine Data System ${ }^{35}$ (MDS). Grid box means for the marine data were created in accordance with the MDS, with the effects of outliers reduced by 'winsorizing' ${ }^{35}$. For grid boxes containing both land and ocean, each component value was weighted according to the proportion of land in the grid box. However, neither component was allowed to be weighted less than $25 \%$ (ref. 36).

31. Lott, N., Baldwin, R. \& Jones, P. The FCC Integrated Surface Hourly Database, a New Resource of Global Climate Data. Technical Report No. 2001-01 (National Climatic Data Center, Asheville, NC, 2001).

32. Worley, S. J., Woodruff, S. D., Reynolds, R. W., Lubker, S. J. \& Lott, N. ICOADS release 2.1 data and products. Int. J. Climatol. 25, 823-842 (2005).

33. Buck, A. L. New equations for computing vapor-pressure and enhancement factor. J. Appl. Met. 20, 1527-1532 (1981).

34. Peixoto, J. P. \& Oort, A. H. The climatology of relative humidity in the atmosphere. J. Clim. 9, 3443-3463 (1996).

35. Rayner, N. A. et al. Improved analyses of changes and uncertainties in sea surface temperature measured in situ since the mid-nineteenth century: The HadSST2 dataset. J. Clim. 19, 446-469 (2006).

36. Jones, P. D. et al. Adjusting for sampling density in grid box land and ocean surface temperature time series. J. Geophys. Res. 106, 3371-3380 (2001). 